Angell realized the crow's similarity to a friend who lived far away and had been ill. Needless to say, Angell later learned that his friend had died the day the crow arrived. They then ask people to report similar experiences. Do not be discouraged, however, as this is the worst such transgression in the book, and it should not obscure the value of the rest. Perhaps you should skip that page.

Candace Savage's Crows is a beautifully crafted celebration of these birds, and places a greater emphasis on the author's and other people's artistic and emotional perception than on the fostering of a specific hypothesis. But she too uses every opportunity to introduce sound evolutionary and ecological concepts, including good descriptions of recent research on crow communication, breeding biology and, to a lesser extent, ecology.

Corvids are without doubt extremely interesting creatures, and research on corvid behaviour is enjoying an unprecedented boom. This is to be celebrated because the mapping of minds that are so different to the better-known minds of mammals may help us think more clearly about the conditions that promote the evolution of advanced cognition. Corvid research may ultimately help in explaining why the primates, which perhaps deserve to be called featherless corvids, have experienced such rapid and differentiated cognitive evolution. Whatever you read, however, remember that crows are just birds, after all.

Alex Kacelnik is in the Department of Zoology,

University of Oxford, South Parks Road,

Oxford OX13PS, UK.

\title{
In the beginning
}

\section{Genesis: The Scientific Quest for Life's Origins \\ by Robert M. Hazen \\ Joseph Henry Press: 2005. 339 pp. \$27.95}

\section{Leslie Orgel}

There aren't many facts or opinions about the origin of life that are universally accepted. Researchers agree that Earth is a little more than 4.5 billion years old. Most would also agree that organisms more or less like bacteria evolved in the first billion or so years of Earth's history, and that darwinian selection, acting on polymeric molecules, was involved. But almost everything else about the origin of life remains obscure. Little is known with certainty about the physical environment in which life evolved or about the detailed steps that that led from unconstrained abiotic chemistry to the organized complexity of biochemistry.

Our limited knowledge of the environment in which life evolved has led to the blossoming of diverse 'scenarios' aimed at describing one or more of the important steps on the road to life. Some are supported by extensive experimental studies, whereas others remain purely hypothetical. This is chaotic intellectual territory, so anyone entering it for the first time needs an accomplished and unbiased guide. Having read Robert Hazen's book Genesis, I can recommend him strongly for the task.

One problem facing authors of introductory books on the origin of life is the popularity of two almost antagonistic scenarios. Stanley Miller's classic experiments on the synthesis of amino acids in a reducing atmosphere led to the idea of a 'prebiotic soup', according to which a genetic system evolved directly in the surface waters of the early Earth. In contrast, Günter Wächtershäuser argued that a complex, non-genetic metabolism evolved on the surface of metal sulphides in geothermal environments, probably in deep-sea vents, before the appearance of a genetic system. Hazen is a metabolist, but he is even-handed in his treatment of the two approaches, at times making it clear that one of his opinions is a minority view.

Like a good guide, Hazen visits all the major

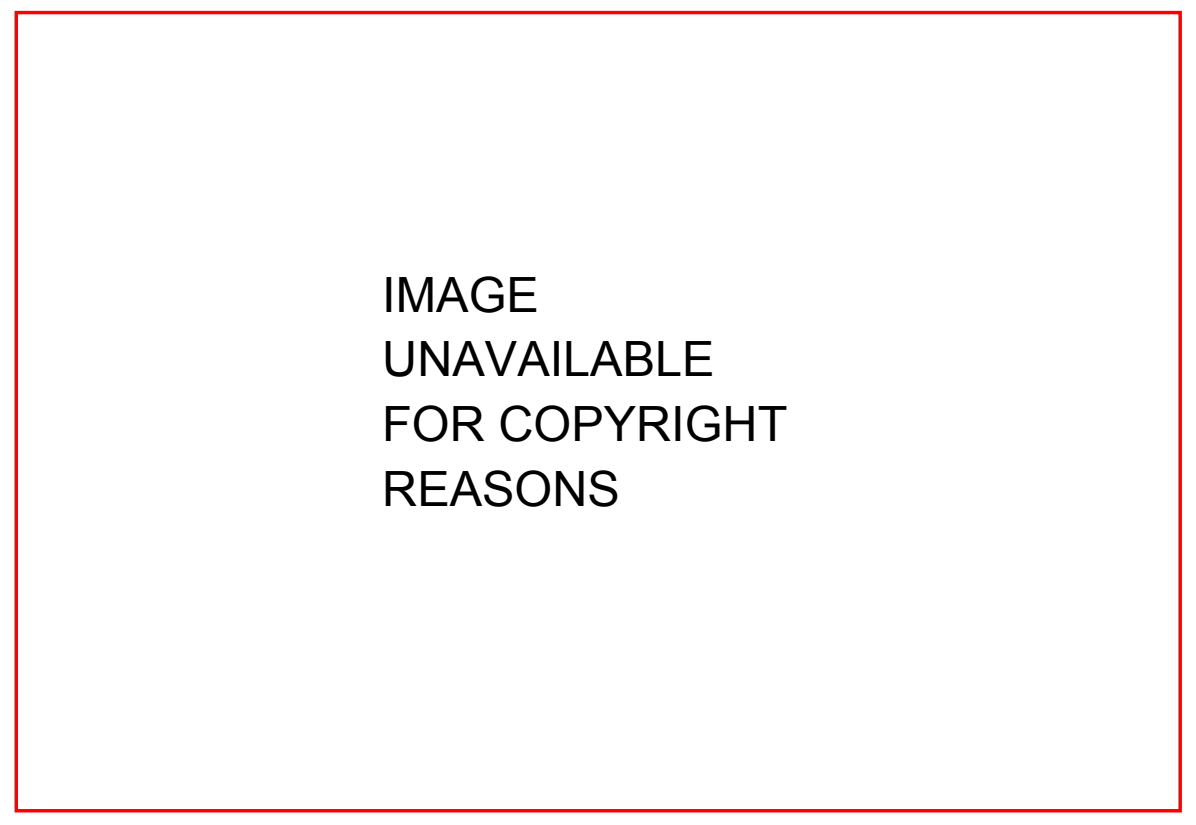

A difficult start: quite how the barren early Earth gave rise to life remains shrouded in mystery.

sites. Naturally, Miller's experiments are on the itinerary, but visits to all the prominent experimental programmes follow. Hazen is sympathetic to theoretical models and includes lengthy descriptions of some highly speculative proposals. However, he always makes it clear that these proposals are speculative and lack experimental support.

Hazen's style is lively and he has a knack for describing clearly and concisely the way that experimental techniques, such as mass spectrometry, work. His peripheral material is well chosen, if not always directly related to the origin of life. I was surprised to learn that if I was reconstituted with all of $\mathrm{my}^{12} \mathrm{C}$ replaced by the ${ }^{13} \mathrm{C}$ isotope, my weight would increase by three pounds. And I was fascinated by his account of a memorable confrontation between experts on Precambrian fossils. Diversions of this kind reduce the fatigue of the journey.

I particularly liked the biographical and autobiographical sections, as it is good to know something about your guide and his friends. Hazen is generous in his brief descriptions of his collaborators' personalities. His accounts of his own experiences in the lab give a vivid picture of what it is like to be an experimentalist. You can imagine him watching intently as the pen of a recorder approaches a critical point, and willing a peak to appear.

The text is accompanied by copious notes and a list of well-chosen references. Unfortunately, there is no indication in the text of their existence. To find the notes you must go to the end of the book, where they are organized by text page, and the references can only be accessed from the notes. This inconvenient arrangement could perhaps be addressed in a later edition.

But this criticism is minor. This book provides the best overview of the 'origin of life' field for the non-specialist reader that I have encountered. I think that even those who are familiar with most of its contents will enjoy the presentation.

Leslie Orgel is at the Salk Institute for Biological Studies, 10010 North Torrey Pines Road, La Jolla, California 92037, USA. 